\title{
Results of Blood Serum from Cancer Treated Hamsters with Infrared Thermal Field and Electromagnetic Fields
}

\author{
Ignat Ignatov $^{1^{*}}$ Reneta Toshkova ${ }^{2} \quad$ Georgi Gluhchev $^{3} \quad$ Christos Drossinakis $^{4}$ \\ 1. DSc, Professor, Scientific Research Center of Medical Biophysics (SRCMB), \\ N. Kopernik Street, 32, Sofia 1111, Bulgaria \\ 2. PhD, MD Professor, Institute of Experimental Morphology, Pathology and Anthropolohy with Museum, \\ Bulgarian Academy of Science (BAS), Acad. G. Bonchev Street, bl. 25, Sofia 1113, Bulgaria \\ 3. $\mathrm{PhD}$, Assoc. Professor; Institute of Information and Communication Technologies, \\ Bulgarian Academy of Science (BAS), Acad. G. Bonchev Street, bl. 2, Sofia 1113, Bulgaria \\ 4. Dr. h.c, Professor, IAWG - INTERNATIONALE Akademie für Wissenschaftliche \\ Geistheilung Königsteiner Str. 61 a, 65929 Frankfurt Höchst
}

\begin{abstract}
A project of the influence of Christos Drossinakis on model biophysical, biochemical and biological systems has been conducted. His influence is with infrared thermal field and electromagnetic fields (e.m. fields). In this study an experiment on hamsters with malignant tumors was performed. The hamsters are prepared by Reneta Toshkova. Spectral analysis methods are Non-equilibrium spectrum (NES) and Differential non-equilibrium spectrum (DNES) for 1\% solutions of blood serum from hamsters with cancer and healthy hamsters were investigated. Drossinakis had an effect on hamsters with cancer. Results are obtained with the DNES method according control serum samples of hamsters with cancer and healthy hamsters. The spectrum was obtained in the range $\left(-0.0937 \mathrm{eV} ; 13.23 \mu \mathrm{m} ; 755 \mathrm{~cm}^{-1}\right)-\left(-0.1387 \mathrm{eV} ; 8.95 ; \mu \mathrm{m} ; 1117 \mathrm{~cm}^{-1}\right)$. The average energy $\left(\Delta \mathrm{E}_{\mathrm{H}} \ldots \mathrm{O}\right)$ of hydrogen $\mathrm{H}$...O-bonds among individual molecules $\mathrm{H}_{2} \mathrm{O}$ after treatment of Drossinakis measured by NESand DNES-methods. The result $\Delta \mathrm{E}=-0.0071 \pm 0.0011 \mathrm{eV}$ is according control serum samples of hamsters with cancer and is $\Delta \mathrm{E}=-0.0035 \pm 0.0011 \mathrm{eV}$ for healthy hamsters. These results suggest the restructuring of $\Delta \mathrm{E}_{\mathrm{H} \ldots \mathrm{O}}$ values among $\mathrm{H}_{2} \mathrm{O}$ molecules with a statistically reliable increase of local extremums in DNES-spectra. Local extremum was obtained at $(-0.1212) \mathrm{eV}$, which is an indicator of anti-inflammatory effect. Also, a local extremum was obtained at $(-0.1387) \mathrm{eV}$, which is an indicator of inhibition of development of tumor cells at the molecular level. The effects of Drossinakis influence- anti-inflammatory, antioxidant, development inhibition of cancer cells are shown. This article deals with the review of the basic biophysical-biochemical and biological processes underlying the influence of Drossinakis. The authors are studying their physical-chemical properties and biophysical and biological effects on the organism of hamsters. Another research by Toshkova have shown that the cancer hamsters influenced by Drossinakis have increased their life span.
\end{abstract}

Keywords: effect of Drossinakis, serum of hamsters, anti-inflammatory, antioxidant, NES, DNES.

DOI: $10.7176 / \mathrm{JHMN} / 58-11$

\section{Introduction}

This report shows the effects of infrared thermal biofiled (ITBF) and electromagnetic fields (e.m. fields) of Drossinakis on hamsters with cancer. There are two control groups of hamsters with cancer and healthy hamsters. The human body emits electromagnetic waves, infrared radiation, biophotons, and bioluminescence. In particular, the results on of spontaneous biophoton emission and delayed luminescence from the human body are studied along with infrared thermography (IRT). It was shown that $1 \mathrm{~cm}^{2}$ of skin generally emits $\sim 85$ photones for $1 \mathrm{~s}$. The intensity of biophoton emission ranges from $10^{-19}$ to $10^{-16} \mathrm{~W} / \mathrm{cm}^{2}$ (approx. $\sim 1-1000$ photons $\mathrm{cm}^{-2} \mathrm{~s}^{-1}$ ).

Electromagnetic fields refer to non-ionizing radiation (NIR), i.g. the radiative energy that, instead of producing charged ions when passing through matter, has sufficient energy only for excitation. Nevertheless it is known to cause biological effects (Kwan-Hoong, 2003). The NIR spectrum is divided into two main regions, optical radiations and electromagnetic fields. The optical spectrum can be further sub-divided into ultraviolet, visible, and infra-red. The electromagnetic fields are further divided into radiofrequency (microwave, very high frequency and low frequency radio wave). NIR encompass the long wavelength $(>100 \mathrm{~nm})$ and low photon energy $(<12.4 \mathrm{eV})$ portion of the electromagnetic spectrum, from $1 \mathrm{~Hz}$ to $3 \cdot 10^{15} \mathrm{~Hz}$.

As a result of research carried out in the 1990-s and subsequent years, it was established the property of animal and plant tissues to generate relatively strong transient NIR electric fields due to mechanical stresses and temperature changes in biological structure (Anderson, 1993). These electric fields are mainly due to the piezoelectric and pyroelectric voltage electric polarization of natural biological structures. Owing to cell metabolism, electric dipoles (polar and ionized molecules) involved in polarization of biostructures are continuously destroyed and restored, i.e. this is a non-equilibrium polarization (Barnes \& Greenebaum, 2006). Such type of non-equilibrium electric polarization is known as a main characteristic of electrets (Gubkin, 1978). The electrets play an important role in functioning of many biological structures as they themselves possess 
electret properties. The bioelectret field registered on the surface of the human body basically are generated by the basal cells of the epidermis (Marino, 1988). Dermis cells adjacent to the bottom layer of basal cells are surrounded by a conductive interstitial fluid, which electric voltage while grounding of the human body is close to zero (so called ground potential). This interstitial fluid screens off electromagnetic fields of underlying tissues. With the average thickness of the epidermis $(\sim 0.1 \mathrm{~mm})$ and the maximum value of electric voltage $(\sim 30.0 \mathrm{~V})$, the electric field strength can reach significant values at $\sim 300000 \mathrm{~V} / \mathrm{m}$ (Seto et al., 1992). The strength of the electric field is quiet sufficient for its influence on the biological processes in cells and surrounding tissues, including the synthesis of proteins and nucleic acids (Liboff at al., 1984; Frey, 1993; Shimizu et al., 1995). This electric field along with the field of transmembrane asymmetry of ions concentrated at inside and outside of the membrane $\left(\sim 10^{5} \mathrm{~V} / \mathrm{cm}^{2}\right)$ can participate in the cooperative effects in cell membrane structures (Holzel \& Lamprecht, 1994; Miller, 1986). Thus, owing to the bioelectret condition of certain subcellular structures in the cell and its surroundings is generated slowly oscillating electric field that is strong enough to influence the biological processes. This field and the electric field due to the piezoelectric voltage and intramembrane electric field formes the total electromagnetic field of the cell and its supracellular structures.

It is known that the human skin emanates electromagnetic waves in close ultraviolet range, optic range and also in close infrared range. Infrared thermal bioradiation is found in the middle infrared range at wavelengths from 8 to $14 \mu \mathrm{m}$. At wavelength of $9.7 \mu \mathrm{m}$ infrared bioradiation has its maximum value at $\mathrm{t}=36.6{ }^{0} \mathrm{C}$. At this temperature the skin emission is closest to the emission of absolute black body (ABB) being at the same temperature. Infrared emission penetrates the skin surface at a depth of $\sim 0.1 \mathrm{~mm}$, and is reflected in accordance with the physical laws of reflection of the visible part of the electromagnetic spectrum. Evidently, radiation energy influences tissues while being absorbed by them. Yu.V. Gulyaev and E.E. Godik (Gulyaev \& Godik, 1984) determined that the threshold of skin sensitivity for infrared radiation compiled $\sim 10^{-14} \mathrm{~W} / \mathrm{cm}^{2}$. When thermal influence is applied to the point of threshold skin sensitivity, there is developed a physiological reaction toward the thermal current. The intensity of the radiated thermal current generated by skin makes up $\sim 2.610^{-2}$ $\mathrm{W} / \mathrm{cm}^{2}$

The second component of electromagnetic waves is bioluminescence (Young \& Roper, 1976; Chang et al., 1998). It is supposed that biophotons, or ultraweak photon emissions of biological objects, are weak electromagnetic waves in the optical range of the spectrum (Cohen \& Popp, 1997). The typical observed emission of biological tissues in the visible and ultraviolet frequencies ranges from $10^{-19}$ to $10^{-16} \mathrm{~W} / \mathrm{cm}^{2}$ ( 1-1000 photons $\mathrm{cm}^{-2} \mathrm{sec}^{-1}$ ) (Edwards et al., 1989; Choi et al., 2002). This light intensity is much weaker than that one to be seen in the perceptually visible and well-studied spectrum of normal bioluminescence detectable above the background of thermal radiation emitted by tissues at their normal temperature (Niggli, 1993).

Bioelectric emission from parts of the human body as thumbs can be easily detected with the method of Color coronal spectral analysis under applying gas electrical discharge of high voltage and frequency developed by I. Ignatov (Ignatov, 2007).

Water seems to be a sensitive model system for studying the interaction with electromagnetic fields and structural research (Ignatov, Antonov, Galabova, 1998). The recent data indicated that water is a complex associated non-equilibrium liquid consisting of associative groups (clusters) containing from 3 to 50 individual $\mathrm{H}_{2} \mathrm{O}$ molecules (Keutsch \& Saykally, 2011). These associates can be described as unstable groups (dimers, trimers, tetramers, pentamers, hexamers etc.) in which individual $\mathrm{H}_{2} \mathrm{O}$ molecules are linked by van der Waals forces, dipole-dipole and other charge-transfer interactions, including hydrogen bonding (Ignatov \& Mosin, 2013). At room temperature, the degree of association of $\mathrm{H}_{2} \mathrm{O}$ molecules may vary from 2 to 21 . The measurements were performed with using NES and DNES methods.

The energy spectrum of water is characterized by a non-equilibrium process of water droplets evaporation; therefore, the term non-equilibrium spectrum (NES) of water is used. The difference $\Delta f(E)=f$ (samples of water) - $\mathrm{f}$ (control sample of water) - is called the "differential non-equilibrium energy spectrum of water" (DNES).

Thus, DNES spectrum is an indicator of structural alterations of water as a result of various external factors. The cumulative effect of these factors is not the same for the control sample of water and the water sample being under the influence of this factor. NES-spectrum of deionized water was used as a model system for studying the interaction of electromagnetic fields with water.

Drossinakis has essential effects of influence evaluated with the methods for registration of e.m. fields biophoton emission, color coronal spectral analysis, water spectrum NES and DNES. These results refer for the research of influence of Drossinakis on hamsters with malignant tumors (Ignatov, Mosin, Niggli, Drossinakis, 2014).

\section{Materials and Methods}

\subsection{NES and DNES Spectral Analysis}

The device for DNES spectral analysis was made by A. Antonov on an optical principle. For this was used a 
hermetic camera for evaporation of water drops under stable temperature $\left(+22-24{ }^{0} \mathrm{C}\right)$ conditions. The water drops were placed on a water-proof transparent pad, which consists of thin maylar folio and a glass plate. The light was monochromatic with filter for yellow color with wavelength at $\lambda=580 \pm 7 \mathrm{~nm}$. The device measures the angle of evaporation of water drops from $72.3^{\circ}$ to $0^{0}$. The DNES-spectrum was measured in the range of $-0.08--0.1387 \mathrm{eV}$ or $\lambda=8.9-13.8 \mu \mathrm{m}$ using a specially designed computer program. The main estimation criterion in these studies was the average energy $\left(\Delta \mathrm{E}_{\mathrm{H} \ldots \mathrm{O}}\right)$ of hydrogen O...H-bonds between $\mathrm{H}_{2} \mathrm{O}$ molecules in water samples and hamster serum blood.

\subsection{Hamsters for research}

In the trials were used hamsters, breed "Golden Syrian", aged 2-4 months with weight around 90-100 g, delivered from breeding organization - Slivnitza- Bulgarian Academy of Sciences (BAS). The animals were grown in standard conditions in the vivarium of the Institute of experimental morphology, pathology and anthropology with museum-BAS, in individual plastic cages, with free access to food and water.

\subsection{Experimental tumor model - Experimental Graffi myeloid tumor in hamsters (solid)}

The experimental Graffisolid tumor is supported monthly in vivo in hamsters from the research team at IEMPAM-BAS (Toshkova, 1995) via subcutaneous transplantation of tumor cells (1-2.106) in the back. Between days 7 and 15 in the area of injection appear tumors, which grow progressively and the hamsters die around 30-35 days after the injecting of tumor cells. In such a tumor model is observed 100\% attachment/, appearance of tumor (=transplantability) and $100 \%$ mortality rate. It is not observed spontaneous regression (=spontaneous shrinking till disappearance of the tumor).

\subsection{IR-spectroscopy}

IR-spectra were registered on Brucker Vertex ("Brucker", Germany) IR spectrometer (a spectral range: average IR $-370-7800 \mathrm{~cm}^{-1}$; visible $-2500-8000 \mathrm{~cm}^{-1}$; the permission $-0,5 \mathrm{~cm}^{-1}$; the accuracy of wave number $-0,1$ $\mathrm{cm}^{-1}$ on $2000 \mathrm{~cm}^{-1}$ ) and on Thermo Nicolet Avatar 360 Fourier-transform IR. These methods were applied for human blood serum.

\subsection{Statistical Processing of Experimental Data}

Statistical processing of experimental data was performed using the statistical package STATISTISA 6.0 using the Student's $t$ - criterion (at $\mathrm{p}<0.05$ ).

\section{Results and Discussion}

\subsection{Clinical studies with hamster serum blood testing}

A convenient method for studying of liquids is non-equilibrium differential spectrum. It was established experimentally that the process of evaporation of water drops, the wetting angle $\theta$ decreases discreetly to zero, and the diameter of the water drop basis is only slightly altered, that is a new physical effect (Antonov, 1995; Antonov \& Yuskesselieva, 1983). Based on this effect, by means of the measurement of the wetting angle within equal intervals of time is determined the function of distribution of $\mathrm{H}_{2} \mathrm{O}$ molecules according to the value of $\mathrm{f}(\theta)$. The distribution function is denoted as the energy spectrum of the water state. The theoretical research established the dependence between the surface tension of water and the energy of hydrogen bonds among individual $\mathrm{H}_{2} \mathrm{O}$-molecules (Antonov, 1995).

For calculation of the function $\mathrm{f}(\mathrm{E})$ represented the energy spectrum of water, the experimental dependence between the wetting angle $(\theta)$ and the energy of hydrogen bonds $(\mathrm{E})$ is established:

where $b=14.33 \mathrm{eV}^{-1}$

$$
f(E)=\frac{14,33 f(\theta)}{\left[1-(1+b E)^{2}\right]^{2}}
$$

The relation between the wetting angle $(\theta)$ and the energy (E) of the hydrogen bonds between $\mathrm{H}_{2} \mathrm{O}$ molecules is calculated by the formula:

$$
\theta=\operatorname{arcos}(-1-14.33 E)
$$

The energy spectrum of water is characterized by a non-equilibrium process of water droplets evaporation, therefore, the term non-equilibrium spectrum (NES) of water is used.

The difference $\Delta f(E)=f$ (Esamples of water) $-f$ (Econtrol sample of water $)$ - is called the "differential non-equilibrium energy spectrum of water" (DNES).

Thus, the DNES spectrum is an indicator of structural changes in water, because the energy of hydrogen bonds in water samples differ due to the different number of hydrogen bonds in water samples, which may result from the fact that different waters have different structures and composition and various intermolecular interactions - various associative elements etc (Ignatov et al, 2014; Ignatov et al., 2015). The redistribution of 
$\mathrm{H}_{2} \mathrm{O}$ molecules in water samples according to the energy is a statistical process of dynamics.

Figure 1 shows the average NES-spectrum of deionised water. On the X-axis are depicted three scales. The energies of hydrogen bonds among $\mathrm{H}_{2} \mathrm{O}$ molecules are calculated in $\mathrm{eV}$. On the $\mathrm{Y}$-axis is depicted the function of distribution of $\mathrm{H}_{2} \mathrm{O}$ molecules according to energies $\mathrm{f}(\mathrm{E})$, measured in reciprocal unit $\mathrm{eV}^{-1}$.

Arrow A designates the energy of hydrogen bonds among $\mathrm{H}_{2} \mathrm{O}$ molecules, which is accepted as most reliable in spectroscopy.

Arrow B designates the energy of hydrogen bonds among $\mathrm{H}_{2} \mathrm{O}$ molecules the value of which is calculated as:

$$
\bar{E}=-0.1067 \pm 0.0011 \mathrm{eV}
$$

Arrow $\mathrm{C}$ designates the energy at which the thermal radiation of the human body, considered like an absolute black body $(\mathrm{ABB})$ with a temperature $+36.6{ }^{0} \mathrm{C}$, is at its maximum.

A horizontal arrow designates the window of transparency of the Earth atmosphere for the electromagnetic radiation in the middle infrared range of the Sun toward the Earth and from the Earth toward the surrounding space. It can be seen that the atmosphere window of transparency almost covers the NES-spectrum of water.

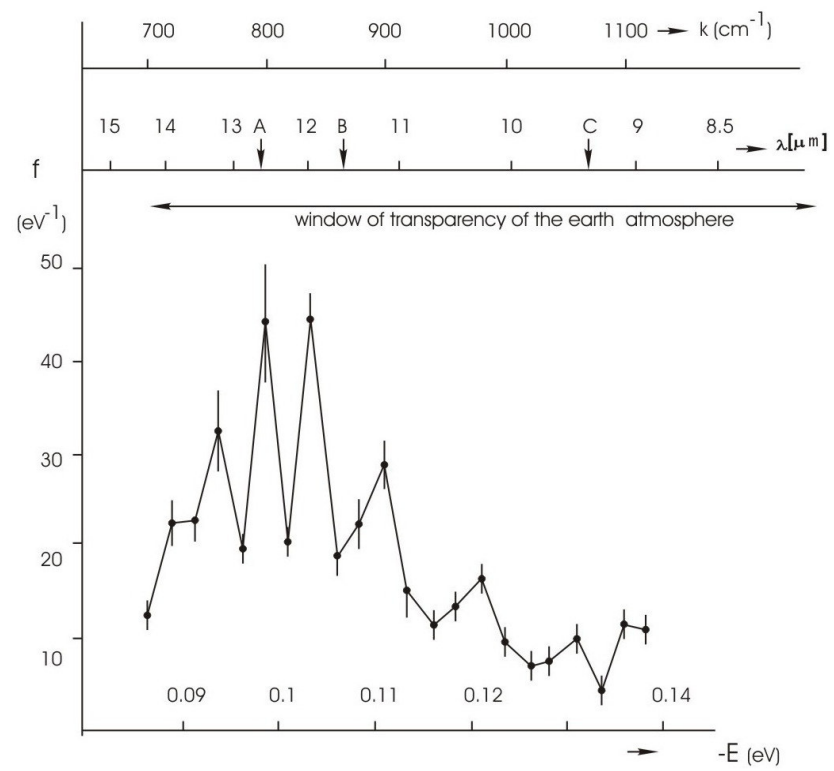

Figure 1: The NES-spectrum of deionized water (chemical purity - 99.99\%; $\mathrm{pH}-6,5-7,5$; total mineralization $200 \mathrm{mg} / \mathrm{l}$; electric conductivity $-10 \mu \mathrm{S} / \mathrm{cm}$ ): the horizontal axis shows the energy of the H...O hydrogen bonds in the associates $-\mathrm{E}(\mathrm{eV})$; the vertical axis - the energy distribution function $-\mathrm{f}\left(\mathrm{eV}^{-1}\right) ; k$ - the vibration frequency of the $\mathrm{H}-\mathrm{O}-\mathrm{H}$ atoms $\left(\mathrm{cm}^{-1}\right) ; \lambda$ - wavelength $(\mu \mathrm{m})$

We have conducted studies of $1 \%(\mathrm{v} / \mathrm{v})$ solution of human blood serum taken from two groups of people between 50 and 70 years of age by IR, NES and DNES spectral analysis (Ignatov, 2012). The first group consisted of people in excellent health. The second group consisted of people in a critical state and patients with malignant tumors. The average energy of hydrogen bonds $\left(\Delta \mathrm{E}_{\mathrm{H} \ldots \mathrm{O}}\right)$ between $\mathrm{H}_{2} \mathrm{O}$ molecules in the blood serum was investigated as the main biophysical parameter. The result was registered as a difference between the NES-

spectrum of $1 \%$ solution of human blood serum and the NES-spectrum of deionized water control sample DNES-spectrum, measured as the difference $\Delta \mathrm{f}(\mathrm{E})=\mathrm{f}$ (samples of water) - $\mathrm{f}$ (control sample of water). The DNES-spectrum obtained from the first group has a local extremum energy $\left(\Delta \mathrm{E}_{\mathrm{H} . . . \mathrm{O}}\right)$ at $\mathrm{E}=-9.1 \pm 1.1 \mathrm{meV}$ and from the second group at $\mathrm{E}=-1.6 \pm 1.1 \mathrm{meV}$. The results between the two groups have a statistical difference in Student's criterion at $\mathrm{p}<0.05$. For the control group of healthy people the value of the largest local maximum in the DNES-spectrum was detected at $\mathrm{E}=-0.1387 \mathrm{eV}$, or at a wavelength $\lambda=8.95 \mu \mathrm{m}$. For the group of people in a critical health state and the patients with malignant tumors, the analogous values of the largest local maximums of the DNES-spectrum shifted to lower energies compared with the control group of people. For a group of people in critical health condition and patients with malignant tumors the greatest values of local extremum in the IR-spectrum are shifted to lower energies relative to the control group. In IR-spectrum of human blood serum are detected 8 local maxima at $\lambda=8.55,8.58,8.70,8.77,8.85,9.10,9.35$ and $9.76 \mu \mathrm{m}$ (Krasnov, Gordetsov, 2009). The resulting peak at $\lambda=8.95 \mu \mathrm{m}$ or $1117 \mathrm{~cm}^{-1}$ in the IR-spectrum (Ignatov, 2012) approaching the peak at $\lambda=8.85 \mu \mathrm{m}$ was monitored by Russian researchers. In the control group of healthy people the average value of the energy distribution function $\mathrm{f}(\mathrm{E})$ at $\lambda=8.95 \mu \mathrm{m}$ compiles $\mathrm{E}=75.3 \mathrm{eV}$, and in a group of people in critical condition $-E=24.1 \mathrm{eV}$. The norm has statistically reliable result for human blood serum for the control group of people having cancer at the local extremum of $\mathrm{f}(\mathrm{E}) \sim 24.1 \mathrm{eV}^{-1}$. The level of reliability of the results is $\mathrm{p}<0.05$ 
according to the Student's t-test. In 1995 were performed DNES-experiments with an impact on tumor mice cells in water solutions containing $\mathrm{Ca}^{2+}$ (Antonov, 1995). There was a decrease in the DNES-spectrum compared with the control sample of cells from a healthy mouse. The decrease was also observed in the DNES-spectrum of human blood serum of terminally ill people relative to that of healthy people. With increasing of age of longliving blood relatives, the function of distribution of $\mathrm{H}_{2} \mathrm{O}$ molecules according to energies at $-0.1387 \mathrm{eV}$ decreases. In this group of tested people the result was obtained by the DNES-method at $\mathrm{E}=-5.5 \pm 1.1 \mathrm{meV}$; the difference in age was of 20-25 years in relation to the control group. It should be noted that many of Bulgarian centenarians inhabit the Rhodopes Mountains areas. Among to the DNES-spectrum of mountain waters the similar to the DNES-spectrum of blood serum of healthy people at $\lambda=8.95 \mu \mathrm{m}$, was the DNES-spectrum of water in the Rhodopes. The mountain water from Teteven, Boyana and other Bulgarian provinces has similar parameters. The value measured at $\mathrm{E}=-0.1387 \mathrm{eV}$ is characteristic for inhibiting the growth of cancer cells. Experiments conducted by A. Antonov with cancer cells of mice in water demonstrated a reduction of this local extremum to a negative value in spectra.

\subsection{Results with spectral analysis with methods NES and DNES of $1 \%$ solutions of blood serums of hamsters \\ NES and DNES of blood serums after influence of Christos Drossinakis}

The research was performed with the following types of $1 \%$ solutions of blood serums

Sample $1-1 \%$ solution of blood serum of hamsters with cancer after influence of Drossinakis

Sample $2-1 \%$ solution of blood serum of hamsters with cancer as control sample

Sample $3-1 \%$ solution of blood serum of healthy hamsters

The average energy $\left(\mathrm{E}_{\mathrm{H} . \ldots \mathrm{O}}\right)$ of hydrogen $\mathrm{H}$...O-bonds among individual $\mathrm{H}_{2} \mathrm{O}$ molecules in $1 \%$ solution of Sample 1 of blood serum of hamsters with cancer after influence of Drossinakis is measured at $\mathrm{E}=-0.1285 \mathrm{eV}$. The result for the Control sample 2 of $1 \%$ solution blood serum from hamsters with cancer is $E=-0.1214 \mathrm{eV}$. The results obtained with the NES method are recalculated with the DNES method as a difference of the NES (Sample 1) minus the NES (Control Sample 2) equalled the DNES spectrum of $1 \%$ solution of blood serum from hamsters.

$\Delta f(E)=f($ sample 1$)-f($ control sample 2$)$

Thus, the result for $1 \%$ solution of blood serum from hamster recalculated with the DNES method is $\Delta \mathrm{E}=-0.0071 \pm 0.0011 \mathrm{eV}$.

The result shows the increasing of the values of the energy of hydrogen bonds in $1 \%$ solution of blood serum of hamsters with cancer after influence of Drossinakis regarding control sample blood serum of hamsters with cancer. The results are effects of structuring of new hydrogen bonds at $(-0.1212 \mathrm{eV})$ with common antiinflammatory effect and new hydrogen bonds at $(-0.1387 \mathrm{eV})$ with anti cancer effects. This shows restructuring of water molecules in configurations of clusters, which influence usefully on human health on molecular and cellular level.

The average energy $\left(\mathrm{E}_{\mathrm{H}} . \mathrm{O}\right)$ of hydrogen $\mathrm{H}$...O-bonds among individual $\mathrm{H}_{2} \mathrm{O}$ molecules in $1 \%$ solution of Sample 1 of blood serum of hamsters with cancer after influence of Drossinakis is measured at $\mathrm{E}=-0.1285 \mathrm{eV}$. The result for the Control sample 3 in $1 \%$ solution of blood serum of healthy hamsters is $E=-0.1250 \mathrm{eV}$. The results obtained with the NES method are recalculated with the DNES method as a difference of the NES (Sample 1) minus the NES (Control Sample 3) equalled the DNES spectrum of 1\% solution of blood serum from hamsters.

$\Delta \mathbf{f}(\mathbf{E})=\mathbf{f}($ sample 1$)-\mathbf{f}($ control sample 3$)$

Thus, the result for $1 \%$ solution of blood serum from hamster recalculated with the DNES method is $\Delta \mathrm{E}=-0.0035 \pm 0.0011 \mathrm{eV}$. The result shows the increasing of the values of the energy of hydrogen bonds in $1 \%$ solution of blood serum of hamsters after influence of Drossinakis regarding control sample blood serum of healthy hamsters.

\subsection{Local extremums of influence of Drossinakis on hamsters}

The local extremums of water samples are detected at $\mathrm{E}=-0.1112 \mathrm{eV}, \mathrm{E}=-0.1212 \mathrm{eV}$ and $\mathrm{E}=-0.1387 \mathrm{eV}$. The value measured at $\mathrm{E}=-0.1212 \mathrm{eV}\left(\lambda=10.23 \mu \mathrm{m} ; 978 \mathrm{~cm}^{-1}\right)$ is characteristic for anti-inflammatory effect (Ignatov, Gluhchev, Karadzhov et al., 2014) The value measured at $\mathrm{E}=-0.1112 \mathrm{eV}\left(\lambda=11.15 \mu \mathrm{m} ; 897 \mathrm{~cm}^{-1}\right)$ is characteristic for the presence of $\mathrm{Ca}^{2+}$ ions in water (Antonov, 1993). The value measured at $\mathrm{E}=-0.1387 \mathrm{eV}(\lambda=$ $8.95 \mu \mathrm{m} ; 1117 \mathrm{~cm}^{-1}$ ) is characteristic for inhibiting the growth of tumor cells (Ignatov, Mosin, 2012). Experiments conducted by Antonov with cancer cells of mice in water demonstrated a reduction of this local extremums to a negative value in DNES spectra for the function of distribution of energies $\Delta \mathrm{f}(\mathrm{E})$ (Antonov, 1993). The results of influence of Drossinakis is effect of structuring of new hydrogen bonds at $(-0.1212 \mathrm{eV})$ with common anti-inflammatory effect and new hydrogen bonds at $(-0.1387 \mathrm{eV})$ with anti tumor effects. This shows restructuring of water molecules in configurations of clusters, which influence usefully on human health 
on molecular and cellular level.

3.4. Mathematical models (Prof. Ignatov, Ass. Prof. Mosin, 2013) of blood serum of hamsters.

The research was performed with the following types of $1 \%$ solutions of blood serums

Sample $1-1 \%$ solution of blood serum of hamsters with cancer after influence of Drossinakis

Sample $2-1 \%$ solution of blood serum of hamsters with cancer as control sample

Sample $3-1 \%$ solution of blood serum of healthy hamsters

The research with the NES method of water drops is received with $1 \%$ solution of blood serum of hamsters with cancer after bio influence of Drossinakis. The mathematical models of $1 \%$ solutions of blood serum of hamsters with cancer after bio influence of Drossinakis give the valuable information for the possible number of hydrogen bonds as percent of $\mathrm{H}_{2} \mathrm{O}$ molecules with different values of distribution of energies according two control samples (Table 1; Figure 2). Sample 2 is $1 \%$ solution of blood serum of hamsters with cancer as control sample. Sample $3-1 \%$ solution of blood serum of healthy hamsters.

These distributions are basically connected with the restructuring of $\mathrm{H}_{2} \mathrm{O}$ molecules having the same energies.

Table 1. The distribution $\left(\%,\left(-\mathrm{E}_{\text {value }}\right) /\left(-\mathrm{E}_{\text {total value }}\right)\right.$ of $\mathrm{H}_{2} \mathrm{O}$ molecules in water samples from Blood Serum of Hamsters. Author: Ignat Ignatov

\begin{tabular}{|c|c|c|c|c|c|c|c|}
\hline $\begin{array}{c}-\mathrm{E}(\mathrm{eV}) \\
\mathrm{x} \text {-axis }\end{array}$ & $\begin{array}{c}1 \% \text { Water } \\
\text { Solution of } \\
\text { Blood Serum } \\
\text { of hamsters } \\
\text { with cancer } \\
\text { after } \\
\text { Drossinakis } \\
\text { influence } \\
\text { y-axis } \\
\left(\%\left(\left(-E_{\text {value }}\right) * /\right.\right. \\
\left(-E_{\text {total value }}\right)^{* *}\end{array}$ & $\begin{array}{c}\text { Control } \\
\text { Sample of } \\
\text { Blood } \\
\text { Serum of } \\
\text { hamsters } \\
\text { with cancer } \\
(\%((- \\
\left.\mathrm{E}_{\text {value }}\right)^{* /} \\
\left(-\mathrm{E}_{\text {total }}\right. \\
\text { value })^{* *}\end{array}$ & $\begin{array}{c}\text { Control } \\
\text { Sample of } \\
\text { Blood Serum } \\
\text { of healthy } \\
\text { hamsters } \\
\left(\%\left(\left(-E_{\text {value }}\right)^{* /}\right.\right. \\
\left(-E_{\text {total }}\right. \\
\text { value })^{* *}\end{array}$ & $\begin{array}{l}-\mathrm{E}(\mathrm{eV}) \\
\mathrm{x} \text {-axis }\end{array}$ & $\begin{array}{c}1 \% \text { Water } \\
\text { Solution of } \\
\text { Blood Serum } \\
\text { of hamsters } \\
\text { with cancer } \\
\text { after } \\
\text { Drossinakis } \\
\text { influence } \\
\text { y-axis } \\
\left(\%\left(\left(-E_{\text {value }}\right)\right.\right. \\
* / \\
\left(-E_{\text {total }}\right. \\
\text { value })^{* *} \\
\end{array}$ & $\begin{array}{c}\text { Control } \\
\text { Sample of } \\
\text { Blood Serum } \\
\text { of hamsters } \\
\text { with cancer } \\
\left(\%\left(\left(-\mathrm{E}_{\text {value }}\right)^{* /}\right.\right. \\
\left(-\mathrm{E}_{\text {total }}\right. \\
\text { value })^{* *}\end{array}$ & $\begin{array}{c}\text { Control } \\
\text { Sample of } \\
\text { Blood } \\
\text { Serum of } \\
\text { healthy } \\
\text { hamsters } \\
(\%((- \\
\left.\mathrm{E}_{\text {value }}\right)^{* /} \\
\left(-\mathrm{E}_{\text {total }}\right. \\
\text { value })^{* *}\end{array}$ \\
\hline 0.0937 & 0 & 0 & 0 & 0.1187 & 0 & 0 & 6.7 \\
\hline 0.0962 & 0 & 0 & 0 & 0.1212 & $21.4^{2}$ & $10.5^{2}$ & $2.3^{2}$ \\
\hline 0.0987 & 0 & 0 & 0 & 0.1237 & 7.1 & 10.5 & 0 \\
\hline 0.1012 & 0 & 10.5 & 11.3 & 0.1262 & 0 & 0 & 6.7 \\
\hline 0.1037 & 0 & 0 & 0 & 0.1287 & 7.1 & 0 & 11.3 \\
\hline 0.1062 & 0 & 105. & 0 & 0.1312 & 7.1 & 10.5 & 6.7 \\
\hline 0.1087 & 0 & 0 & 0 & 0.1337 & 7.1 & 10.5 & 18.5 \\
\hline 0.1112 & $0^{1}$ & $0^{1}$ & $0^{1}$ & 0.1362 & 7.1 & 5.5 & 0 \\
\hline 0.1137 & 14.3 & 105 & 6.7 & 0.1387 & $28.8^{3}$ & $10.5^{3}$ & $18.5^{3}$ \\
\hline 0.1162 & 0 & 10.5 & 11.3 & - & - & - & \\
\hline
\end{tabular}

$\mathrm{E}=-0.1112 \mathrm{eV}$ is the local extremum for effect on the nervous system

$\mathrm{E}=-0.1212 \mathrm{eV}$ is the local extremum for anti-inflammatory effect

$\mathrm{E}=-0.1387 \mathrm{eV}$ is the local extremum for inhibition of development of tumor cells of molecular level

Notes:

* The result $\left(-\mathrm{E}_{\mathrm{value}}\right)$ is the result of hydrogen bonds energy for one parameter of (-E)

** The result $\left(-\mathrm{E}_{\mathrm{value}}\right)$ is the total result of hydrogen bonds energy 


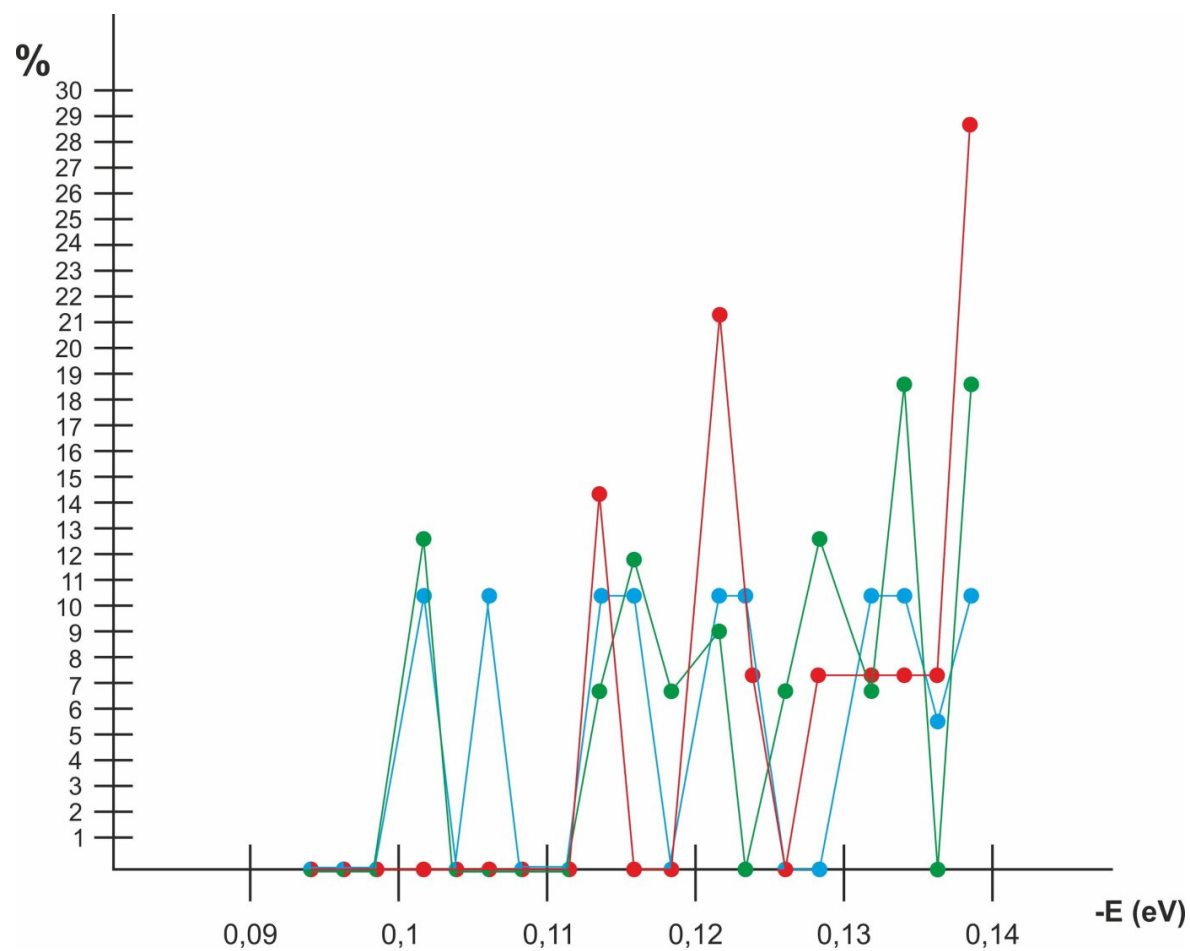

Fig. 2. Mathematical model (Ignatov, Mosin, 2013) of $1 \%$ water solutions of $1 \%$ solution of serums from hamsters

Figure 2 shows the distribution $\left(\%,\left(-\mathrm{E}_{\text {value }}\right) /\left(-\mathrm{E}_{\text {total value }}\right)\right.$ of $\mathrm{H}_{2} \mathrm{O}$ molecules in and $1 \%$ of water solution of serums from hamsters

(red line) - after bioinfluence of Drossinakis on hamsters with cancers

(blue line) - hamsters with cancers

(green line) - healthy hamsters

\section{Notes:}

$\mathrm{E}=-0.1212 \mathrm{eV}$ is the local extremum for anti-inflammatory effect

$E=-0.1387 \mathrm{eV}$ is the local extremum for inhibition of development of tumor cells of molecular level

\subsection{Conclusions from mathematical models}

Sample $1-1 \%$ solution of blood serum of hamsters with cancer after influence of Drossinakis

Sample $2-1 \%$ solution of blood serum of hamsters with cancer as control sample

Sample $3-1 \%$ solution of blood serum of healthy hamsters

3.5.1. Conclusions from mathematical models of Sample 1 with $1 \%$ solution of blood serum of hamsters with cancer after influence of Drossinakis and Sample 2 with $1 \%$ solution of blood serum of hamsters with cancer as control sample

The experimental data obtained testified the following conclusions from the mathematical model of in Sample 1 with $1 \%$ solution of blood serum of hamsters with cancer after influence of Drossinakis and Sample 2 with $1 \%$ solution of blood serum of hamsters with cancer as control sample. The object of analysis is distribution (\%, ($\left.E_{\text {value }}\right) /\left(-E_{\text {total value }}\right)$ of water molecules in mathematical models of Sample 1 with $1 \%$ solution of blood serum of hamsters with cancer after influence of Drossinakis and Sample 2 with 1\% solution of blood serum of hamsters with cancer as control sample. For the value $\mathrm{E}=-0.1212 \mathrm{eV}$ or $\lambda=10.23 \mu \mathrm{m}$ there is the bigger local extremum $\left(21.4\left(\%,\left(-\mathrm{E}_{\text {value }}\right) /\left(-\mathrm{E}_{\text {total value }}\right)\right)\right.$ corresponding to the re-structuring of hydrogen bonds among $\mathrm{H}_{2} \mathrm{O}$ molecules for anti inflammatory effect. The distribution $\left(\%,\left(-\mathrm{E}_{\text {value }}\right) /\left(-\mathrm{E}_{\text {total value }}\right)\right.$ of water molecules in Sample 1 according Control sample $2\left(10.5\left(\%,\left(-E_{\text {value }}\right) /\left(-E_{\text {total value }}\right)\right)\right.$ is different. This difference may indicate on the different number of hydrogen bonds in water samples, as well as their physical parameters, resulting in different distribution of $\mathrm{H}_{2} \mathrm{O}$ molecules and different values of $\mathrm{H}_{2} \mathrm{O}$ molecules with ratios of $\left(-\mathrm{E}_{\text {value }}\right) /\left(-\mathrm{E}_{\text {total value }}\right)$.

Particularly it was observed the statistical re-structuring of $\mathrm{H}_{2} \mathrm{O}$ molecules in water samples according to the energies. The experimental data may prove that stipulates the restructuring of $\mathrm{H}_{2} \mathrm{O}$ molecules on molecular level and may be used for anti-inflammatory effects with influence of immunology system. However, for the value $\mathrm{E}=-0.1387 \mathrm{eV}$ or $\lambda=8.95 \mu \mathrm{m}$ there is biggest local extremum $\left(28.8\left(\%,\left(-\mathrm{E}_{\text {value }}\right) /\left(-\mathrm{E}_{\text {total value }}\right)\right)\right.$ corresponding to the re-structuring of hydrogen bonds among $\mathrm{H}_{2} \mathrm{O}$ molecules for inhibition of development of tumor cells of molecular level. The distribution $\left(\%,\left(-\mathrm{E}_{\mathrm{value}}\right) /\left(-\mathrm{E}_{\text {total value }}\right)\right.$ of water molecules in Sample 1 according Control sample $2\left(10.5\left(\%,\left(-\mathrm{E}_{\text {value }}\right) /\left(-\mathrm{E}_{\text {total value }}\right)\right)\right.$ is different. 
The experimental data for the effect of Drossinakis may prove that stipulates the restructuring of $\mathrm{H}_{2} \mathrm{O}$ molecules on molecular level and the biophysical effects are:

$\mathrm{E}=-0.1212 \mathrm{eV}$ is the local extremum for anti-inflammatory effect

$\mathrm{E}=-0.1387 \mathrm{eV}$ is the local extremum for inhibition of development of tumor cells of molecular level

3.5.2. Conclusions from mathematical models of Sample 1 with $1 \%$ solution of blood serum of hamsters with cancer after influence of Drossinakis and Sample 3 with $1 \%$ solution of blood serum of healthy hamsters as control sample

The experimental data obtained testified the following conclusions from the mathematical model of in Sample 1 with $1 \%$ solution of blood serum of hamsters with cancer after influence of Drossinakis and Sample 3 with $1 \%$ solution of blood serum of healthy hamsters as control sample. The object of analysis is distribution (\%, ($\left.E_{\text {value }}\right) /\left(-E_{\text {total value }}\right)$ of water molecules in mathematical models of Sample 1 with $1 \%$ solution of blood serum of hamsters with cancer after influence of Drossinakis and Sample 2 with 1\% solution of blood serum of hamsters with cancer as control sample. For the value $\mathrm{E}=-0.1212 \mathrm{eV}$ or $\lambda=10.23 \mu \mathrm{m}$ there is the bigger local extremum $\left(21.4\left(\%,\left(-E_{\text {value }}\right) /\left(-E_{\text {total value }}\right)\right)\right.$ corresponding to the re-structuring of hydrogen bonds among $\mathrm{H}_{2} \mathrm{O}$ molecules for anti inflammatory effect. The distribution $\left(\%,\left(-\mathrm{E}_{\text {value }}\right) /\left(-\mathrm{E}_{\text {total value }}\right)\right.$ of water molecules in Sample 1 according Control sample $2\left(2.3\left(\%,\left(-\mathrm{E}_{\text {value }}\right) /\left(-\mathrm{E}_{\text {total value }}\right)\right)\right.$ is different. This difference may indicate on the different number of hydrogen bonds in water samples, as well as their physical parameters, resulting in different distribution of $\mathrm{H}_{2} \mathrm{O}$ molecules and different values of $\mathrm{H}_{2} \mathrm{O}$ molecules with ratios of $\left(-\mathrm{E}_{\text {value }}\right) /\left(-\mathrm{E}_{\text {total value }}\right)$. Particularly it was observed the statistical re-structuring of $\mathrm{H}_{2} \mathrm{O}$ molecules in water samples according to the energies. The experimental data may prove that stipulates the restructuring of $\mathrm{H}_{2} \mathrm{O}$ molecules on molecular level and may be used for anti-inflammatory effects with influence of immunology system. However, for the value $E=-0.1387$ $\mathrm{eV}$ or $\lambda=8.95 \mu \mathrm{m}$ there is biggest local extremum $\left(28.8\left(\%,\left(-\mathrm{E}_{\mathrm{value}}\right) /\left(-\mathrm{E}_{\text {total value }}\right)\right)\right.$ corresponding to the restructuring of hydrogen bonds among $\mathrm{H}_{2} \mathrm{O}$ molecules for inhibition of development of tumor cells of molecular level. The distribution $\left(\%,\left(-\mathrm{E}_{\text {value }}\right) /\left(-\mathrm{E}_{\text {total value }}\right)\right.$ of water molecules in Sample 1 according Control sample 2 $\left(18.5\left(\%,\left(-E_{\text {value }}\right) /\left(-E_{\text {total value }}\right)\right)\right.$ is different.

The experimental data for the effect of Drossinakis may prove that stipulates the restructuring of $\mathrm{H}_{2} \mathrm{O}$ molecules on molecular level and the biophysical effects are:

$\mathrm{E}=-0.1212 \mathrm{eV}$ is the local extremum for anti-inflammatory effect

$\mathrm{E}=-0.1387 \mathrm{eV}$ is the local extremum for inhibition of development of tumor cells of molecular level

\section{Conclusions}

The basic conclusion is that Drossinakis is able to increase the average energy of hydrogen bonds among water molecules in the blood of hamsters with cancer after treatment compared to the average energy of hydrogen bonds among water molecules in the blood of non-treated hamsters with cancer and healthy hamsters as control groups.

The mathematical model of blood serum solution of hamsters with cancer after the Drossinakis' influence gives significant information about the possible number of hydrogen bonds as a percent of $\mathrm{H}_{2} \mathrm{O}$ molecules with different distribution of energy relative to the same number in the two control groups.

As a result of different energies of hydrogen bonds, the surface tension of the blood serum solution of cancer hamsters is increased after the treatment relative to the control samples. This effect is connected with the preservation and increase in the energy of the biochemical processes between water molecules and biomolecules.

\section{References}

Abdullah, A.M., Abdelsalam, E., Abdullah, B. \& Khaled, A. (2012) Antioxidant Effects of Zamzam Water in Normal Rats and Those Under Induced-oxidant Stress, Journal of Medicinal Plants Research, 6(42):55075512.

Adelman, R., Saul, R. \& Ames, B. (1988) Oxidative Damage to DNA: Relation to Species Metabolic Rate and Life Span, $P N A S$, 85(8): 2706-2708.

Anderson, L.E. (1993) Biological Effect of Extremely Low Frequency Electromagnetic Fields: in vivo Studies. Am. Ind. Hig. Assoc. J., 54: 186-196.

Antonov, A. Galabova, T. (1992) Ext. Abstr. Of the $6^{\text {th }}$ National Conference of Biomedical Physics and Engeneering, 60 .

Antonov, A., Galabova, T., Todorova, L., Tomov, (1993) Observatoire de Montagne de Mussala OM2, Edit par J.P. Carbonel and J. N. Stamenov, Sofia, 113.

Antonov, A. (1995) Research of the Non-equilibrium Processes in the Area in Allocated Systems. Dissertation thesis for degree "Doctor of physical sciences", Blagoevgrad, Sofia.

Antonov, A. \& Yuskesselieva, L. (1985) Selective High Frequency Discharge (Kirlian Effect). Acta Hydrophysica, 5: 29.

Atanasov, A., Karadzhov, S., Ivanov, E., Mosin, O.V. \& Ignatov I. (2014) Study of the Effects of 
Electrochemical Aqueous Sodium Chloride Solution (Anolite) on the Virus of Classical Swine Fever Virus. Mathematical Models of Anolyte and Catolyte as Types of Water. Journal of Medicine, Physiology and Biophysics, 4: 1-26.

Barnes, F.S. \& Greenebaum, B. (eds.) (2006) CRC Handbook on Biological Effects of Electromagnetic Fields, 3d Edition, Boca Raton: CRC Press, 2, 1-960.

Brubach, J.B., Mermet, A., Filabozzi, A., Gerschel, A. \& Roy, P. (2005) Signatures of the Hydrogen Bonding in the Infrared Bands of Water. J. Chem. Phys., 122: 184509.

Burger, O., Baudish, A. \&Vaupel, J. W. (2012) Human Mortality Improvement in Evolutionary Context, PNAS, 109(44): 18210-18214.

Choi, C., Woo, W.M., Lee, M.B. at al. (2002) Biophoton Emission from the Hands. J. Korean Physical. Soc., 41:275-278.

Cleary, S.F. (1993) A Review of in vitro Studies: Low-frequency Electromagnetic Fields. J. Am. Ind. Hyg. Assoc, 54(4): 178-185.

Chang, J.J., Fisch, J. \& Popp, F.A. (eds) (1998) Biophotons. Dordrecht, Kluwer Academic Publishers, 1-417

Cohen, D. (1968) Magnetoencephlalography: Evidence of Magnetic Fields Produced bi Alpha-rhythm Currents. Science, 161(3843): 784-786.

Cohen, S. \& Popp, F.A. (1997) Biophoton Emission of the Human Body. Journal of Photochemistry and Photobiology B: Biology, 40(2): 187-189.

Edwards, R. et al. (1989) Light emission from the Human Body. Complement Med. Res., 3:16.

Eisenberg, D. \& Kauzmann, W. (1969) The Structure and Properties of Water. Oxford University Press, London. Frey, A.H. (1993) Electromagnetic Field Interactions with Biological Systems. FASEB Journal, 7(2): 272-281

Gluhchev, G., Ignatov, I. Karadzhov, S., Miloshev, G., Ivanov, N.\& Mosin, O.V. (2015) Electrochemically Activited Water. Biophysical and Biological Effects of Anolyte and Catholyte as Types of Water, Journal of Medicine, Physiology and Biophysics, 10: 1-17.

Goryainov S.V. (2012) A Model of Phase Transitions in Double-well Morse Potential: Application to Hydrogen Bond. Physica B, 407, 4233-4237.

Gluhchev, G., Ignatov, I., Karadzhov, S., Miloshev, G., Ivanov, N.\&Mosin, O.V.(2015) Studying the Antimicrobial and Antiviral Effects of Electrochemically Activated Nacl Solutions of Anolyte and Catholyte on a Strain of E. Coli DH5 and Classical Swine Fever (CSF) Virus, European Journal of Medicine, 9 (3): 124-138.

Gluhchev, G., Ignatov, I., Karadzhov, S., Miloshev, G., Ivanov, I. \& Mosin, O. V. (2015) Studying of Virucidal and Biocidal Effects of Electrochemically Activated Anolyte and Catholyte Types of Water on Classical Swine Fever Virus (CSF) and Bacterium E. coli DH5, Journal of Medicine, Physiology and Biophysics, 13:1-17.

Gluhchev, G., , Ignatov, I., Karadzhov, S., Miloshev, G., Ivanov, N. \& Mosin, O.V. (2015) Electrochemically Activited Water: Biophysical and Biological Effects of Anolyte and Catholyte Types of Water, 7. (1): 1226.

Gubkin, A.N. (1978) Electrets. Moscow, Nauka, 1-192.

Gulyaev, Yu.V. \& Godik, E.E. (1984) On the Possibilities of the Functional Diagnostics of the Biological Subjects Via Their Temporal Dynamics of the Infrared Images, USSR Academy Nauk Proceedings/Biophysics, 277: 1486-1491.

Gulyaev, Yu.V. \& Godik, E.E. (1990) Human and Animal Physical Fields. Scientific American, 5: $74-83$.

Gulyaev, Yu.V. \& Godik, E.E. (1991) Functional Imaging of the Human Body. IEEE Engineering in Medicine and Biology, 10: 21-29.

Holzel, R. \& Lamprecht, I. (1994) Wirkungen Elektromagnetischer Felder auf Biologische Systeme, Nachrichtentech Elektron, 44(2): 28-32.

Howard, C. \& Hopps (1986) Chemical Qualities of Water that Contribute to Human Health in a Positive Way, Science of the Total Environment, 54: 207-216.

Ignatov, I., Mosin, O. V. \& Naneva, K. (2012) Water in the Human Body is Information Bearer about Longevity. Euromedica, Hanover: 110-111.

Ignatov, I., Antonov, A.\&Galabova, T. (1998) Medical Biophysics - Biophysical Fields of Man, Gea Libris, 171.

Ignatov, I. (2007) Energy Biomedicine, Origin of Living Matter, “Informationability” of Water, Biophysical Fields, ICH, Munich, 1-136

Ignatov I. (2012) Conference on the Physics, Chemistry and Biology of Water, Water in the Human Body is Information Bearer about Longevity, NY, Vermont Photonics.

Ignatov, I. \& Mosin, O.V. (2013) Structural Mathematical Models Describing Water Clusters. Journal of Mathematical Theory and Modeling, 3(11): 72-87.

Ignatov, I., Mosin, O.V., Velikov, B., Bauer, E. \& Tyminski, G. (2014) Longevity Factors and Mountain Water 
as a Factor. Research in Mountain and Field Areas in Bulgaria, Civil and Environmental Research, 6 (4): 51-60.

Ignatov, I., Mosin, O.V. \& Velikov, B. (2014) Longevity Factors and Mountain Water of Bulgaria in Factorial Research of Longevity, Journal of Medicine, Physiology, Biophysics,1:13-33.

Ignatov, I., Mosin,O.V., Velikov, B., Bauer, E. \& Tyminski, G. (2014) Research of Longevity Factors and

Mountain Water as a Factor in Teteven Municipality, Bulgaria, Journal of Medicine, Physiology and Biophysics, 2: $37-52$

Ignatov, I. \& Mosin, O. V. (2014) Nature of Haydrogen Bonds in Liquids and Crystals. Ice Crystal Modifications and Their Physical Characteristics, Journal of Medicine, Physiology and Biophysics, 4: 58-80.

Ignatov, I., Mosin, O.V., Velikov, B., Bauer, E. \& Tyminski, G. (2014) Research of Longevity Factors and Mountain Water as a Factor in Teteven, Yablanitsa and Ugarchin Municipalities, Lovech Region, Bulgaria, Journal of Health, Medicine and Nursing, 4: 21-36.

Ignatov, I. Mosin, O.V., Velikov, B. Bauer, E. \& Tyminski, G. (2014) Mountain Water as Main Longevity Factor in Research of Phenomenon of Longevity in Mountain Areas in Bulgaria, European Journal of Molecular Biotechnology, 4 (2): 52-71.

Ignatov, I. \& Mosin, O. V. (2014) Hydrogen Bonds among Molecules in Liquid and Solid State of Water. Modifications of Ice Crystals, Journal of Health, Medicine and Nursing, 5: 56-79.

Ignatov, I. \& Mosin, O.V. (2014b) Methods for Measurements of Water Spectrum. Differential Non-equilibrium Energy Spectrum Method (DNES), Journal of Health, Medicine and Nursing 6: 50-72.

Ignatov, I. \& Mosin, O.V. (2014) Isotopic Composition of Water as Main Factor for Longevity, Drug Development and Registration, 9 (4): 146-155. [in Russian].

Ignatov, I., Mosin, O. V., Velikov, B. \& Bauer, E. (2014) Influence of Isotopic Composition of Water with Varying Deuterium Content in Composition with Mountain Water of Bulgaria on Human Longevity, Journal of Medicine, Physiology and Biophysics, 7: 46-78.

Ignatov, I., Karadzhov, S., Atanasov, A., Ivanov, E. \& Mosin, O.V. (2014) Electrochemical aqueous sodium chloride solution (anolyte and catholyte) as types of water. Mathematical models. Study of effects of anolyte on the virus of classical swine fever virus. Journal of Health, Medicine and Nursing, 8: 1-28.

Ignatov, I., Mosin, O.V. \& Velikov, B. (2015) Mountain Water as a Factor of Human Longevity. Local Extremum at $8.95 \mu \mathrm{m}$ in Spectrum of Water as Indicator for Health and Longevity, Journal of Medicine, Physiology and Biophysics, 9: 51-81.

Ignatov, I. \& Mosin, O.V. (2015) Methods for Research of Mountain and Melt Water as Factor of Longevity. Chemical Composition, NES and DNES Methods for Spectral Analysis. Effects of Calcium, Magnesium, Zinc and Manganese, Advances in Physics Theories and Applications, 44: 48-64.

Ignatov, I. \& Mosin, O.V. (2015b) Water: Solid and Liquid Phases. Nano Structures in the Water in Solid and Liquid Phases, Journal of Medicine, Physiology and Biophysics, 9: 82-109.

Ignatov, I., Mosin, O.V., Kirov, P. (2016) Mathematical Model of Kangen Water ${ }^{\circledR}$ Biophysical and Biochemical Effects of Catholyte, Advances in Physics Theories and Applications, 20: 33-55.

Ignatov, I., Gluhchev, G., Karadzhov, S., Miloshev, G., Ivanov, I.\&Mosin, O. V. (2015) Preparation of Electrochemically Activated Water Solutions (Catholyte/Anolyte) and Studying of their Physical-Chemical Properties, Journal of Medicine, Physiology and Biophysics, 13:18-38.

Ignatov, I.\&Mosin,O.V. (2015) Nanostructures in Solid and Liquid Phases of Water, Journal of Medicine, Physiology and Biophysics, 12:31-57.

Ignatov, I.\&Mosin, O. V. (2014) Isotopic Composition of Water as Main Factor for Longevity, Drug Development and Registration, 9 (4): 146-155.

Ignatov, I. \&Mosin, O.V. (2015) Methods for Research of Mountain and Melt Water as Factor of Longevity. Chemical Composition, NES and DNES Methods for Spectral Analysis. Effects of Calcium, Magnesium, Zinc and Manganese, Advances in Physics Theories and Applications, 44:48-64.

Ignatov, I., Mosin, O.V., Karadzhov, S., Miloshev, G.\&Ivanov, N. (2015) The Evaluation of Mathematical Model of Interaction of Electrochemically Activated Water Solutions (Anolyte and Catholyte) with Water, European Reviews of Chemical Research, 2 (4): 72-86.

Ignatov, I. (2018) Research of the Factors of Health and Longevity for the Population in Bulgaria, Bulgarian Journal of Public Health, 10 (1): 52-85.

Isaacs E.D., Shukla A., Platzman P.M, et all. (2000) Compton Scattering Evidence for Covalency of the Hydrogen Bond in Ice, J. Phys. Chem. Solids, 61, 403-406.

Keutsch F. \& Saykally R. (2011) Water Clusters: Untangling the Mysteries of the Liquid, One Molecule at a Time. PNAS, 98(19), 105330-10540.

Krasnov, V.V. \& Gordetsov, A.S. (2009) Infrared spectral analysis of blood serum as level of disturbances of metabolic processes in infusion children pathology. Clinical Medicine: 83-94 [in Russian].

Kulling, S.E.\&Rawel, H.M. (2008) Aronia Melanocarpa - A Review on the Characteristic Components and 
Potential Health Effects, Planta Medica, 74 (13):1625-34.

Kuriyama et al. (2006) Green Tea Consumption and Mortality due to Cardiovascular Disease, Cancer, and all Causes in Japan: The Ohsaki Study, The Journal of the American Medical Association, 296 (10): 12551265.

Kwan-Hoong, Ng. (2003) Non-ionizing Radiations - Sources, Biological Effects, Emissions and Exposures. Proceedings of the International Conference on Non-Ionizing Radiation at UNITEN (ICNIR2003). Electromagnetic Fields and Our Health. 20-22 October 2003.

Lis, G., Wassenaar, L.I. \& Hendry, M.J. (2008) High-precision Laser Spectroscopy D/H and ${ }^{18} \mathrm{O} /{ }^{16} \mathrm{O}$ Measurements of Microliter Natural Water Samples. Anal. Chem., 80(1): 287-293.

Liu K., Cruzan J.D. \& Saykally R.J. (1996) Water Clusters. Science Magazine, 271(5251), 929-933.

Loboda O. \& Goncharuk V. (2010) Theoretical Study on Icosahedral Water Clusters. Chemical Physics Letters, 484(4-6), 144-147.

Lis, G., Wassenaar, L.I. \& Hendry, M.J. (2008) High-precision Laser Spectroscopy D/H and ${ }^{18} \mathrm{O} /{ }^{16} \mathrm{O}$ Measurements of Microliter Natural Water Samples. Anal. Chem., 80(1): 287-293.

Lv.J., Wang, W., Krafft, T., Li, Y., Zhang, F.\&Yuan, F. (2011) Effects of Several Environmental Factors on Longevity and Health of the Human Population of Zhongxiang, Hubei, China, Biol. Trace Elem. Res., 143 (2):702:716.

Luck W., Schiöberg D. \& Ulrich S. (1980) Infared Iinvestigation of Water Structure in Desalination Membranes. J. Chem. Soc. Faraday Trans., 2(76), 136-147.

Niggli, H. (1993). Artificial Sunlight Irradiation Induces Ultra Weak Photon Emission in Human Skin Fibroblasts, Journal of Photochemistry and Photobiology B: Biology, 18 (2-3): 281-285.

Maheshwary S., Patel N., Sathyamurthy N., Kulkarni A.D. \& Gadre S.R. (2001) Structure and Stability of Water Clusters $\left(\mathrm{H}_{2} \mathrm{O}\right)_{\mathrm{n}}, \mathrm{n}=8-20$ : An Ab Initio Investigation. J. Phys. Chem., 105, 10525-10537.

Mariani, E. et al. (2006) Antioxidant Enzyme Activities in Healthy Old Subjects: Influence of Age, Gender and Zinc Status: Results from the Zincage Project, Biogerentology, 7 (5-6): 391:398.

Marino, A.A (Ed.) (1988) Modern Bioelectricity. Marieel Dekker, New York, Basel, ISBN 0-8247-7788-3.

Marinov, M. \& Ignatov, I. (2008) Color Kirlian Spectral Analysis. Color Observation with Visual Analyzer. Euromedica, Hanover, 57-59.

Miller, M.W. (1986) Extremely Low Frequency (ELF) Electric Fields: Experimental Work on Biological Effects. CRC Handbook of Biological Effects of Electromagnetic Fields, 138-168.

Malhotra, A.,\&Dhawan, D. K. (2008) Zinc Improves Antioxidative Enzymes in Red Blood Cells and Hematology in Lithium-Treated Rats, Nutr. Res., 28(1):43-50

Matsumoto, M. et al. (2004) Gastroprotective Effect of Red Pigments in Black Chokeberry Fruit (Aronia melanocarpa Elliot) on Acute Gastric Hemorrhagic Lesions in Rats, J. Agric. Food Chem., 52 (8): 22262229.

Michaelides A. \& Morgenstern K. (2007) Ice Nanoclusters at Hydrophobic Metal Surfaces. Nat. Mat., 6: 597599.

Mocchegiani, E. (2007) Zinc, Metallothioneins, and Longevity- Effect of Zinc Supplementation: Zincage Study, Ann N. Y. Acad. Sci, 1119: 129-146.

Pasichnyk I. Everaers R. \& Maggs A.C. (2008) Simulating van der Waals-interactions in Water/HydrocarbonBased Complex Fluids. J. Phys. Chem. B, 112(6), 1761-1764.

Pauling L. (ed.) (1960) The Nature of the Chemical Bond and the Structure of Molecules and Crystals, New York: Cornell University Press.

Pimentel G.C. \& McClellan A.L. (1960) The hydrogen bond (L. Pouling, Ed). New York: Reinhold Publishing Co.

Pocock, S.J, Shaper, A.G. \& Packham, R.F. (1981) Studies of Water Quality and Cardiovascular Disease in the United Kingdom, Sci. Total Environ., 18: 25-34.

Orgel, L. (1963) The Maintenance of the Accuracy of Protein Synthesis and its Relevance to Aging, Biochemistry, 49: 517-521.

Saykally, R. (2005) Unified description of temperature-dependent hydrogen bond rearrangements in liquid water. PNAS, 102(40): 14171-14174.

Seto, A. et al. (1992) Detection of extraordinary large bio-magnetic field strength from human hand. Acupuncture Electrother Res. Int. J., 17:75.

Simon, M. et al. (2006) How Much Calcium Is in Your Drinking Water? A Survey of Calcium Concentrations in Bottled and Tap Water and Their Significance for Medical Treatment and Drug Administration, HSS Journal, 2(2): 130-135.

Shelton, R.M. (1991) Aloe Vera: Its Chemical and Therapeutic Properties, Int. Journal Dermatol, 30: 679-683.

Shimizu H., Suzuki, Y. \& Okonogi, H. (1995) Biological Effects of Electromagnetic Fields. Nippon Eiseigaki Zasshi., 50(6): 919-931. 
Sykes M. (2007) Simulations of RNA Base Pairs in a Nanodroplet Reveal Solvation-Dependent Stability. PNAS, 104(30), 12336-12340.

Tokmachev A.M., Tchougreeff A.L. \& Dronskowski R. (2010) Hydrogen-Bond Networks in Water Clusters $\left(\mathrm{H}_{2} \mathrm{O}\right)_{20}$ : An Exhaustive Quantum-Chemical. European Journal of Chemical Physics and Physical Chemistry, 11(2), 384-388.

Toshkova R. (1995), Attemps for Immunomodulation in Hamsters with Transplanted Myeloid Tumor, Previously Induced by Graffi Virus. Bulgarian Academy of Sciences, PhD Dissertation, Sofia.

Toshkova R., Dimitrova P., Ivanova E., Dolaska P., Angelova M., Pashova S., Slokoska L. Wittke F., Hoffman R., \&Voelter W. (2000), Immunoprotective Effect of $\mathrm{Cu} / \mathrm{Zn}$ Superoxide Dismutase on Myeloid Graffi Tumor-Bearing Hamsters, Z. Naturforsch, 55.

Toshkova, R., Krasteva, N., Nikolov, S. (2008) Immunorestoration and Augmentation of Mitogen Lymphocyte Response in Graffi Tumor Bearing Hamsters by Purified Saponin Mixture from Astragalus corniculatus, Phytomedicne, 15 (10): 876-881

Tsai C.J. \& Jordan K.D. (1993) Theoretical Study of the $\left(\mathrm{H}_{2} \mathrm{O}\right)_{6}$ Cluster. Chem. Phys. Letters, 213, $181-188$.

Valcheva-Kuzmanova, S.V.\&Belcheva, A. (2006) Current Knowledge of Aronia Melanocarpa as a Medicinal Plant. Folia Med., 48 (2):11-7.

Wang F \& Jordan K.D. (2003) A Parallel Tempering Monte Carlo Investigation of $\left(\mathrm{H}_{2} \mathrm{O}\right)_{6}{ }^{-}$. J. Chem. Phys., 119, 11645-11653.

Woodhead, R. (1984) Molecular Biology of Aging. NY, Basic Life Science, 35, pp. 34-37.

Young, R.E. \& Roper, C.F. (1976) Bioluminescent Countershading in Midwater Animals: Evidence from Living Squid, Science, 191(4231): 1046-1048.

Yuan, Y.\&Shao, Y. (2002) Systematic Investigation of Alkali Metal Ion transfer Across the Micro-and-nanowater/1,2-dichloroethane interfaces facilated by dibenzo-18-crown-6, The Journal of Physical Chemistry B, 106 (32): 7809-7814.

Zink, A. et al. (2014) Outbreak of Microsporum audouinii in Munich - the Return of Infectious Fungi in Germany, Mycose, 57 (12): 765-770. 